\title{
Development and Revelation of Japanese Sport Climbing
}

\author{
CHEN Ruizhi ${ }^{1,3, a}$, LI Yuan ${ }^{1,2,3, b^{*}}$ \\ ${ }^{I}$ Department of Physical Education, China University of Geosciences, Wuhan, Hubei, China \\ ${ }^{2}$ Postdoctoral Research Station, China University of Geosciences, Wuhan, Hubei, China \\ ${ }^{3}$ China Institute of Mountaineering and Outdoor Recreation, Wuhan, Hubei, China \\ achenruizhi913@foxmail.com \\ b*liyuan@cug.edu.com
}

\begin{abstract}
Sport climbing has made its way into in the Olympic Games, Youth Olympic Games and Asian Games successively in recent years, thereby turning into a new point of increase of the competitive sports in different countries. Japan, the fastest growing country in sport climbing over the past few years, has proven to be a formidable force in many of the world's major climbing events. This paper explored the national culture, management system, talent training system and competition system reflected in the development of Japanese sport climbing on the basis of observing the process of Japan's rise in the field of sport climbing in the world, with the aim of providing significant reference for the development of sport climbing.
\end{abstract}

Keywords: sport climbing, Japan, development, Olympic Games

\section{THE RISE OF SPORT CLIMBING IN JAPAN}

\subsection{History of Sport Climbing in Japan}

Rock climbing was birthed from mountaineering. Early European climbers frequently made use of climbing techniques during mountaineering, and climbing was established as an independent sport around the 1880s. The development of Japanese rock climbing is basically in line with the evolution of rock climbing in the world. Traditional climbing gained popular in Japan in the early 1970s, with people climbing with a variety of aids. At the end of 1970s, Yosemite National Park in the United States, with free climbing as the main form, turned into a mecca for rock climbing in the world, while free climbing gradually took off in Japan. People no longer finished climbing lines with aids, and started to improve their climbing ability through daily climbing training. Rock climbing also acquired the features of safety, fairness, ease of promotion and spectacle that competitive sports have, and the prototype of sport climbing began to take shape [1]. In 1977, sport climbing was established as an official event of the National Sports Festival, the largest national sporting event in Japan with a long history, but the climbing form and rules were not unified at that time. In 1991, the Japanese Alpine Club formulated a policy to further promote sport climbing and initiated competitions, and in the same year Japan won a silver medal in the difficulty event of the 1st IFSC Climbing World Championships in Frankfurt, Germany; the following year, the Japan Mountaineering Association carried out a reform of the sport, making sport climbing a key development sport, and artificial rock walls started to be built throughout the country. In the mid-1990s, as more climbing gyms were built, a portion of the climbers shifted from traditional climbing to indoor artificial rock walls. Its convenience and safety also attracted an increasing number of participants, and sport climbing in Japan began to grow rapidly. In the $21 \mathrm{st}$ century, rock climbing grew into the most popular sport climbing sport in Japan, and a large number of rock climbing and difficulty events were held nationwide, leading to the rapid development of sport climbing in Japan.

\subsection{Competitive Strength of Japanese Sport Climbing}

In the past five years, Japan has been the fastest growing country in sport climbing in the world, showing great performance in the two major sport climbing events in the world, the World Cup of Rock Climbing and the 
IFSC Climbing World Championships. Counting the number of medals won by the top five countries in the total number of medals in the above two events from 2007-2018, which can reveal the rapid growth of Japan's strength, and also the obvious advantage of Japan in the world of sport climbing from the number of individual medals. Over recent years, Japan is slowly increasing the number of awards in difficult events while continuously widening the gap of climbing events with other countries.

It is worth noting in particular that the rules for calculating the ranking for the Tokyo Olympics in 2021 are that each athlete needs to compete in three individual events: difficulty, rock climbing and speed. Therefore, athletes need to be at the world's top level in at least two events at the same time to have a greater chance of entering the finals of the all-around event, and Japanese athletes are better adapted to the above rules.

\section{TRACING JAPANESE SPORT CLIMBING BACK TO ITS ORIGIN}

\subsection{Intrinsic driving force of the national character and cultural genes}

The Japanese people have developed a rich national spirit of "aggressiveness" in order to maintain their survival and development. After World War II, Japan, as a defeated country, built an economic power from the ruins in only 30 years, largely on account of its national character and culture [2]. Besides, Japan has a worldwide recognized "artisan character", where skilled people have been respected and called "craftsmen" since the Shogunate era. The artisan culture, while rooted in dedication and unwavering loyalty to the craft, pursues perfection and excellence in all walks of life [3].

The history of Japanese mountaineering is a profound testimony to the characteristics of the Yamato people. Influenced by the belief of mountains in Japanese religious culture, Japanese people have a strong attachment to "mountains", such as Mount Fuji, which is the spiritual and faithful support of Japanese people [4]. In 1902, the first Japanese mountaineering organization "Japanese Alpine Club" was established, and the book On the Japanese Landscap by shiga shigetaka was published, which led to the emergence of the "Taisho Mountaineering Fever". Although the highest mountain in Japan, Mount Fuji, is only 3,775.63 meters, Japan has occupied an important position in the world of mountaineering and has produced a number of worldclass mountaineers. For example, in 1921, Yuko Maki made the first ascent of the Eiger along the northeast ridge of the "most difficult route in the Alps"; in the 1950s, a Japanese climbed the world's eighth highest peak, Manaslu; in 1986, a Japanese climbing team completed the world's 14 peaks above 8,000 meters; 80year-old Japanese Yuichiro Miura is currently the oldest climber to summit Mount Everest; and Japanese climbers have won the Golden Ice Axe Award, the highest award in the world for mountaineering, five times [5].

Sport climbing served as a complement to mountaineering in the field of competitive sports. Japan first held sport climbing competitions in the same period as Europe in 1980, and ushered in the era of sport climbing specialization in parallel with the world's climbing powerhouses, capturing the silver medal in the men's difficulty competition at the first IFSC Climbing World Championships in 1991. In Japan, the purpose of sport climbing is to promote health through exercise, to improve skills and competitive performance, and to share the values shown by sport climbing, so a strong climbing culture has developed [6].

\subsection{Rich and accessible natural resources and many artificial sites as the physical guarantee for rock climbing}

The abundant natural rock fields have nurtured the sport of rock climbing, while the construction of a large number of artificial rock fields has popularized the sport. Besides, good management has made full use of these climbing places. These factors provide a good practical foundation for the development of rock climbing in Japan. The unique geological features of the Japanese archipelago determine the abundance of natural rock walls mainly for rock climbing. In 1987, the climbers selected by the Chinese Mountaineering Association observed that Japanese climbers were delicate, skillful and standardized when they studied in Japan [8].

Climbing venues are a crucial factor in the development of sport climbing. Following the invention of artificial climbing walls imitating nature in the 1980s, which opened the era of sport climbing, artificial rock walls soon replaced natural rock walls as the main venues for climbing activities [1]. The Japan Sports Association (JASA) built the first national artificial rock wall for sport climbing in 1995 and was responsible for its direct management. For example, the Fukui Climbing Center, which is operated and managed by the Fukui Mountaineering Federation and the Sport Climbing Association, is responsible for the training of local competitive athletes. Therefore, some young athletes have also been selected for the Japanese national climbing team [7]. It is evident that the importance of local climbing competent associations in sport climbing has a greater relationship with the development of highquality competitive athletes.

Besides, Japanese commercial climbing gyms are highly specialized and have formed a mature chain business model. Large climbing gyms with a climbing area of more than 1,000 square meters have sprung up one after another, featuring a very rich set of climbing holds and a full range of supporting facilities such as restaurants, showers and physical therapy recovery rooms 
that fully attract and satisfy potential climbers. As of December 2018, there are at least 540 commercial climbing venues in Japan, an almost six-fold increase in 10 years, with nearly 100 in Tokyo alone. Commercial climbing facilities have been built in all 47 prefectural regions and above[10]. Japanese climbing gyms have a unique and particularly rich variety of artificial climbing holds, and all of the world's major climbing holds manufacturers have distributors in Japan. The more climbing holds and routes an athlete climbs, the richer his or her personal technical arsenal will be, and in turn, the more adaptable he or she will be to climb routes designed by different styles of setters in competition [11]. Also, Japanese national team athletes have free training rights at commercial climbing gyms nationwide, and thus commercial climbing gyms have become the main connection between professional sport climbing and popular climbing in Japan.

\subsection{A complete organizational management structure with multiple departments working together for the development of sport climbing}

The management structure of sport climbing in Japan is quite complete, including government departments, private associations, and scientific research institutions, all of which coordinate with each other. Of these, government departments are the core of the organization that provides strong organizational support for the development of sport climbing. The Ministry of Education, Culture, Sports, Science and Technology (MEXT), of the central government, is the central agency for decision-making on competitive sports in Japan. It supports the development of competitive sports, including sport climbing, in terms of competitive sports management, sports promotion programs, improvement strategies for competitive ability, anti-doping, and awards for excellent coaches and athletes [12], and has an independent administrative legal entity, the Japan Sport Council (JAC). The practical management of sport climbing in Japan is carried out by the Japanese Mountaineering and Sport Climbing Association (JMSCA), the Japanese Olympic Committee (JOC) and the Japan Sport Association (JASA) under the guidance of the MEXT, with JMSCA as the hub of the management structure. The close cooperation between JMSCA and JASA during the "non-Olympic" period before 2016 laid a solid foundation for the rapid improvements of sport climbing, with a much higher degree of cooperation between the two than with JOC. However, following the admission of sport climbing to the Olympic Games in 2016, JASA and JOC have acted as the main financial sources for sport climbing in Japan, providing extensive support in the areas of mass climbing, climbing events, athlete training, and scientific research, respectively.
JMSCA is the authority for sport climbing approved by the Cabinet Office, formerly known as the Japanese Mountaineering Association, and renamed as the Japanese Mountaineering and Sport Climbing Association following the introduction of sport climbing into the Olympic Games in 2016, consisting of 47 prefectural mountaineering federations (associations) and sport climbing federations (associations), and the climbing program division of the National Federation of Higher Education Sports. JMSCA, as a public interest organization that oversees mountaineering and climbing in Japan, undertakes the formulation of national strategic policies related to sport climbing. It also cooperates with JASA and JOC to guide and manage sport climbing activities nationwide, including the promotion and popularization of the sport climbing, the organization of domestic and international sport climbing competitions, the improvement of the technical level of sport climbing, the training and qualification of sport climbing instructors, the development of sport climbing competition rules, the research and development, testing and accreditation of sport climbing-related equipment and international climbing exchanges [13], with six departments under it . Besides, over the past 30 years, local mountaineering and sport climbing associations in Japan have undertaken a lot of practical work, such as building a number of climbing gyms across the country, especially for rock climbing [1]; training and sending climbers recommended by prefectures to competitions according to the requirements of JMSCA, and giving the recommended outstanding athletes priority to register for national competition qualifiers and national youth climbing events. In turn, the competitive level of these competitions has been also ensured on this basis [7]. At present, JMSCA has formulated policies and measures in several areas, which strongly guarantee the rapid development of sport climbing .

The JOC is responsible for the international exchange of sport climbing, selection of athletes for international events, training of athletes, inviting elite athletes from around the world to Japan, and participating in the development of national sport climbing plans. Since the introduction of sport climbing into the Olympic Games, the JOC has selected six athletes each for men and women under the Gold Medal Program and provided financial support to strengthen athletes. In 2017, sport climbing was included as an official event of the Japan Junior Olympics hosted by the JOC, and was directly involved in the selection and deployment of athletes for international competitions in sport climbing, etc. Among the JOC's priority support programs for the Tokyo Olympics, the sport climbing for men is classified as one of the eight A priority support programs that may win multiple medals, and sport climbing for women is also classified as one of the $11 \mathrm{~B}$ priority support programs that are expected to win medals [14]. The JOC is now focusing on securing health science training, competition 
intelligence collection and analysis, and 1-2-year international exchange dispatches for coaches and athletes for competitive climbers participating in the Olympic Games through a variety of training programs and scientific research specialties based on the Gold Program on the basis of the Gold Program [12].

\subsection{A complete athlete training system and “consistency" guidelines}

One of the most fundamental reasons for the rapid development of sport climbing in Japan is the efficient and scientific athlete training system. The pyramid process of the training system for building a high-level sport climbing athlete in Japan can be divided into three stages: training of youth athletes, selection of youth for national competitions, and training and strengthening of outstanding athletes. The "consistency" guideline is adopted throughout the process of training Japanese sport climbers, which runs through the different age and skill level development stages of athletes, guaranteeing the scientific and personalized development of athletes in different periods [15]. Supported by a complete and coherent tournament system, a foreign exchange system and a good security policy, it gives an optimal structure to the development system of Japanese sport climbers.

\subsection{A well-developed event system guaranteeing a smooth flow of outstanding athletes in the event}

The development of Japanese sport climbing is only 40 years old, and the participating population is relatively small compared to traditional competitive sports. However, since the 1980s, Japan has gradually built a sport climbing event system characterized by abundant tiers and detailed events, which has ensured a smooth flow of athletes in the competition system. The Japanese climbing competition system has a clear hierarchy and wide coverage, ensuring both grassroots events and upward mobility of amateur and youth competitive climbers. On this basis, the athletes are selected for intensive instruction, training, and re-selection, and the national youth team is formed to participate in international youth tournaments, where they represent Japan in world-class tournaments after being trained in international youth competitions.

Besides, Japanese sport climbing competitions set up the difficulty race, rock climbing race and speed race as three sub-events separately, and the national level single event is held only once a year. As a selection event for Olympic athletes, the JOC Japan Junior Olympics only has one event of difficulty race; there is no special event for speed race in Japan, only JMSCA regularly holds a test conference to record the speed results from March to May every year, and the test results are used as a reference for the selection of future team members.
However, the refinement of the difficulty and rock climbing events has improved the quality of climbing events and allowed athletes to focus on their strengths, reducing the density of athletes' participation and giving them sufficient training and rest time.

\subsection{Close international exchanges with climbing powerhouses enhancing the training of outstanding athletes}

In April 1886, W.P. Haskett Smith climbed the famous Napes Needle rock wall in the English Lake District using Free Solo (unprotected hand climbing), which marked the birth of rock climbing as a new sport [17-18]. For more than 130 years, Europe, the birthplace of rock climbing, has been the leader in climbing technology for a long time. Japan has combined the most current sport climbing training technology with scientific research to summarize the sports training theory suitable for its competitive climbers and pay attention to analyze the management experience of traditional climbing powerhouses in the joint training.

Austria is one of the world's top sport climbing powers, and the Japanese climbing national team has traveled to Austria for joint training three times in 2006, 2007, and 2009, and invited Austrian coaches to teach and coach the Japanese national climbing team in 2010. The Japanese Medical Science Council also sent experts to conduct scientific research on joint training from 2009 to 2010 [16] to understand Austrian climbing training theories and methods and to statistically analyze the technical improvement of Japanese athletes. Besides, since 2011, the Japanese climbing team has hired top French setters to come to Japan for guidance when training, to develop tactics and target training with the goal of international competition, and to learn the rules of international events. Through years of external study, Japanese female athletes won the World Cup of Rock Climbing in 2013 [19]; the above training theories and methods were also validated in the World Youth Championships, where 24 medals were won in the 2017 World Youth Championships, 10 ahead of the secondplaced US delegation, and a total of 14 medals were won by Japan at the 2018 World Youth Climbing Championships ahead of the second-placed Russia with 7 medals.

\subsection{The scientific research providing theoretical guidance and intellectual support for the development of rock climbing practice}

With the advanced technology today, the development of sports is increasingly dependent on a strong foundation of sports science research and a strong ability to apply scientific research results. Japan attaches great importance to the important role of scientific and technological information in the development of sport 
climbing, and for many years has devoted itself to collecting information from various countries for review and analysis. The National Center for Mountaineering Education (NCME), established by the MEXT in July 1967 , at that time aimed to promote the healthy and safe development of mountaineering and climbing in Japan by training mountaineering and climbing instructors and providing mountaineering and climbing information to prevent mountaineering accidents [20]. NCME has been publishing Mountaineering Training since 1985, which includes a large number of research results related to climbing sports.

Besides, CINII, the largest database of academic papers in Japan, currently contains more than 2,900 journal papers and 30 doctoral dissertations with the title of "rock climbing" and "climbing" since 1893, and the contents are mainly on technical characteristics of rock climbing, sports training, physiological, biochemical and sports medicine. It also includes topics such as climbing site and equipment management and climbing history and culture, providing theoretical guidance and intellectual support for the development of mountaineering and climbing practice in Japan [21].

\section{CONCLUSION}

As a brand new official event at the 2021 Tokyo Olympics, sport climbing has been the focus of many countries' Olympic preparations as international competition intensifies. Japan has rapidly emerged as a world leader in recent years, and has shown outstanding adaptability to the current Olympic "all-around model" rules. The rise of Japan's sport climbing has deep-seated historical and cultural reasons, natural environment, management system, sports training and competition, international exchange and scientific research support. In recent years, sport climbing has been growing rapidly in different countries, and a number of young athletes with great potential for development have emerged, winning many international competitions and making great progress in training all-round athletes. However, some countries also face outstanding problems such as weak mass base, lack of professional talents and insufficient competition system. Taking Japan's experience as a reference, we should give full play to the advantages of each country and establish a development model of sport climbing that suits the characteristics of national conditions. In particular, we should take measures to increase the promotion and publicity, increase the population base of rock climbing, and promote the common development of competitive rock climbing and mass rock climbing. We should also pay attention to the planning of reserve talents, improve the level of echelon construction, and establish a sustainable talent training system and mechanism. Besides, we should take into account the popularization and improvement, and gradually establish a dynamic event system that helps the development of the project. Moreover, it is suggested to pay attention to international exchanges and cooperation, and improve the scientific training level. Last but not least, we should increase the investment in scientific research, improve the level of scientific research, and guarantee the scientific development of competitive rock climbing, so as to achieve a greater breakthrough in the development of sport climbing.

\section{REFERENCES}

[1] Dong Soo Ae. Current status of sport climbing[J]. Journal of Mountaineering Training,2003,18(1):2833.

[2] Wu Dan Mao, Gao Yabiao. Alloy culture--the secret of Japan's success[J]. Management World, 1988,4(3):206-218.

[3] Zhu Qin, Liu Peifeng. The production of Japanese artisan spirit and its historical changes[J]. Social Sciences in Yunnan,2018, (03):90-96.

[4] Rina Fujita. Guo Moruo's experience of studying abroad: "scenery" and "inner world" in the present day $[\mathrm{J}]$. Journal of Modern Chinese Literature,2012,4(5):42-46.

[5] The official website of Golden Ice Axe [EB/OL]. [2018-12-04]. http://www.pioletsdor.net/index.php/en/

[6] Tanemura Seki. Competitive mountaineering[J]. Mountaineering Training,1993,8(1):79-82.

[7] Shinji Mizumura, Naoto Hagamada, Yoshiko Nishitani. The importance of public facilities in sport climbing[C]. Journal of Critical Theory, Meiji University, Millstone No.509. Tokyo: Meiji University Journal of Educational and Critical Studies,2015:91-116.

[8] Xie Yishan. Rock climbing enters the Olympic Games to continue the inseparable relationship between Chinese and Japanese mountaineering [EB/OL]. [2016-08-04]. http://dszx.sport.gov.cn/n5411/c737077/content.ht $\mathrm{ml}$

[9] Japanese Mountaineering and Sport Climbing Association. Climbing Competition Facilities [EB/OL]. [2018-12-04]. https://www.jmasangaku.or.jp/sports/?ca $=16$

[10] Mitchell A.C., Bowhay A., Pitts J. Relationship between anthropometric characteristics of indoor rock climbers and top roped climbing performance[J]. J Strength Cond Res,2011, 25(Supplement 1):94-95.

[11] Japan Rock Climbing Net. Find a Gym by Prefecture 
[EB/OL]. [2018-12-04]. http://bouldering-log.com

[12] Hu Qilin. Study on the development strategy of competitive sports in Japan[J]. Journal of Wuhan Institute of Physical Education,2017,51(6):95-100.

[13] Japan Mountaineering and Sport Climbing Association. About Japan Mountaineering and Sport Climbing Association[EB/OL]. [2018-12-04]. https://www.jma-sangaku.or.jp/?ca=1

[14] He Wenjie. Japan Sports Agency announces key support projects for Tokyo Olympics [EB/OL]. [2017-09-18]. http//www.sportinfo.net.cn/

[15] Jing Junjie, Xiao HuanYu. The development and inspiration of Japanese sports policy in the $21 \mathrm{st}$ century $[\mathrm{J}]$. Journal of Shanghai University of Sport,2014,38(1):31-35.

[16] Nishitani Y, Yamamoto M. A training system for sport climbing in Austria[J]. Journal of Mountaineering Training,2011.26(1):5-10.

[17] Thompson S. Unjustifiable risk: The story of British climbing[M]. Cumbria: Cicerone Press,2011.

[18] Hankinson A. The mountainmen: An early history of rock climbing in north wales-From Its Beginning to 1914[M]. Ibadan: Heinemann Educational Books,2004.

[19] IFSC.Rankings[EB/OL]. [2018-12-04]. http://www.ifsc-climbing.org/index.php/worldcompetition/rankings

[20] Japan Sport Council. History of the National Mountaineering Training Institute[EB/OL]. [201812-04]. https://www.jpnsport.go.jp/tozanken/annai/tabid/61 /Default.aspx

[21] Yoshiko Nishitani, Masayoshi Yamamoto. Development and application of available handfinger strength test for sport climbers[J]. Journal of Mountaineering Training,2016,31(1):19-23.

[22] The Outdoor Foundation.Outdoor Participation Report 2018[EB/OL]. [2018-07-17]. https://outdoorindustry.org/resource/2018-outdoorparticipation-report/ 